\title{
CSF gusher complicating cochlear implant surgery
}

\author{
Soorya Pradeep 주, Arun Alexander
}

ENT, Jawaharlal Institute of Postgraduate Medical Education and Research, Puducherry, Puducherry, India

\section{Correspondence to} Arun Alexander: arunalexandercmc@gmail.com

Accepted 12 November 2021

\section{DESCRIPTION}

A cerebrospinal fluid (CSF) gusher may be defined as a profuse pulsatile egress of clear fluid which occurs on making an opening in the cochlea. ${ }^{12} \mathrm{~A}$ gusher may be encountered in 1 in 100 cochlear implantations, ${ }^{3}$ but in patients with inner ear malformations, its incidence increases to $40 \%-50 \% .^{45}$ CSF leaks are believed to occur due to an abnormal communication between the CSF in the internal acoustic meatus and the perilymph in the inner ear. ${ }^{12} \mathrm{~A}$ careful analysis of preoperative CT and MRI is crucial to look for anatomic abnormalities which may predispose to gushers. However, gushers may be encountered even in cases where the preoperative scans appear normal (1.5\%-2.5\%), ${ }^{3}{ }^{7}$ as current imaging modalities are sometimes unable to pick up minor communications between the internal acoustic canal and the cochlea.

A 14-month-old prelingually deaf boy underwent cochlear implantation with an Advanced Bionicsslim J electrode. Preoperative CT showed normal cochlear anatomy with normal dimensions of the cochlear and vestibular aqueduct. No defects could be detected in the lamina cribrosa or the modiolus. MRI showed the presence of bilateral vestibulocochlear nerves of appropriate diameter (figure 1). Implantation was done through the facial recess via the extended round window approach.

On opening the round window, a CSF leak was detected (video 1). Controlled hyperventilation was initiated and intravenous propofol and mannitol were administered. The electrode array was inserted into the cochleostomy to stop the leak, but the pressure of the gusher was such that the electrode kept getting extruded. Pieces of periosteum
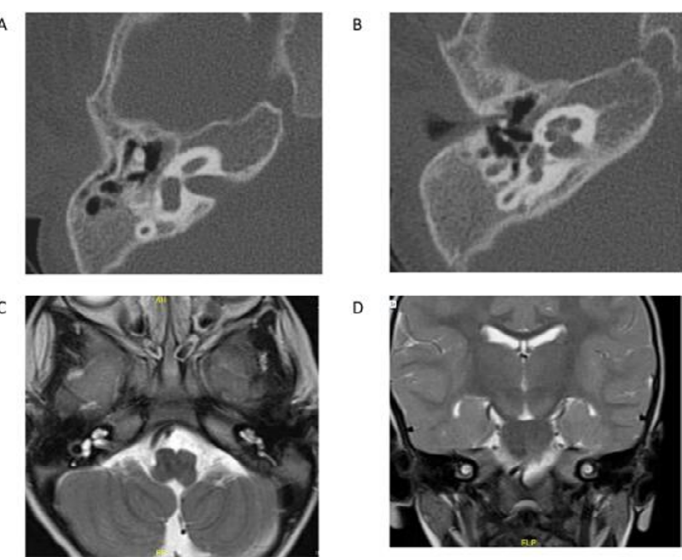

Figure 1 Preoperative scans showing normal anatomy of the cochlea and the internal acoustic meatus. (A) CT temporal bone axial section, (B) CT temporal bone coronal section, (C) T2-weighted MRI axial section and (D) T2-weighted MRI coronal section.

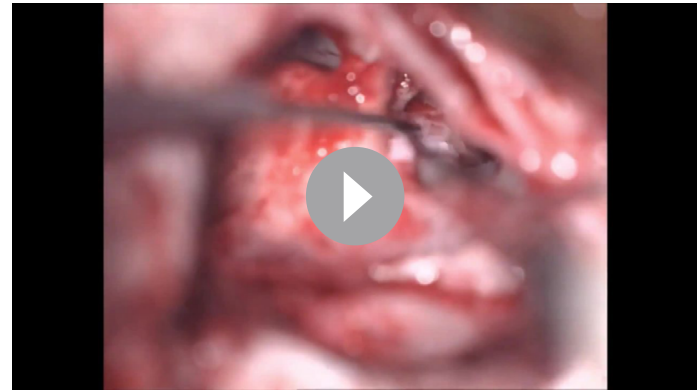

Video 1 Intraoperative management of a CSF gusher during cochlear implantation.

were initially inserted around the electrode, but the leak continued to persist. Thin strips of temporalis fascia were then harvested and packed into the cochleostomy and around the electrode. Periosteum was further packed around the electrode to achieve a water-tight seal. Fibrin glue was applied.

Intraoperative neural response imaging showed normal evoked compound action potential in all 16 electrodes. A postoperative X-ray confirmed the accurate positioning of the electrode (figure 2). A lumbar drain was not used. The postoperative period was uneventful, and the child was discharged on the 10th postoperative day. The device was switched on after 3 weeks and the patient continues to receive auditory-verbal therapy to date.

The successful management of a CSF gusher relies on the surgeon's ability to create a water-tight seal around the cochleostomy. This may be achieved by the folowing.

1. Placing the patient in a reverse trendelenburg position. $^{135}$

2. Initiating controlled hyperventilation to decrease the venous return to the heart and hence

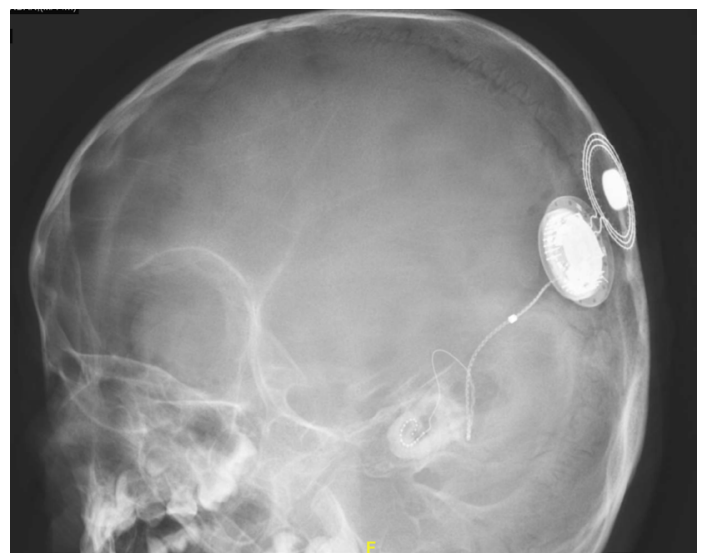

Figure 2 Postoperative X-ray in modified Stenver view showing normal placement of the electrode. 
decrease cerebral perfusion, hypercapnia results in vasoconstriction of cerebral vessels. ${ }^{35}$

3. Administration of hypotensive agents such as propofol and diuretics like mannitol. ${ }^{3}$

4. Insertion of the electrode after waiting for the flow of CSF to slow down. ${ }^{1-3}$

5. Packing periosteum around the electrode array. ${ }^{35}$

6. Packing strips of fascia into the basal turn and around the electrode. ${ }^{135}$

7. Post-operative acetazolamide. ${ }^{6}$

8. Continuous postoperative lumbar drainage. ${ }^{16}$

In rare cases where the above measures fail to control the leak, the surgeon may be required to completely obliterate the middle ear and close the Eustachian tube with connective tissue, ${ }^{5}$ failing which a subtotal petrosectomy may be necessary. ${ }^{16}$

\section{Learning points}

Cerebrospinal fluid gushers during cochlear implantation are mostly encountered in patients with inner ear malformations.

- However, gushers may be encountered even in patients with normal preoperative scans.

- In most cases, a gusher may be managed by creating a watertight seal around the cochleostomy site.

Contributors SP: drafting the manuscript, acquisition of data and editing the video. AA: patient care and editing the manuscript.
Funding The authors have not declared a specific grant for this research from any funding agency in the public, commercial or not-for-profit sectors.

Competing interests None declared.

Patient consent for publication Consent obtained from parent(s)/guardian(s).

Provenance and peer review Not commissioned; externally peer reviewed.

Case reports provide a valuable learning resource for the scientific community and can indicate areas of interest for future research. They should not be used in isolation to guide treatment choices or public health policy.

\section{ORCID iDs}

Soorya Pradeep http://orcid.org/0000-0003-4164-127X

Arun Alexander http://orcid.org/0000-0003-1026-4678

\section{REFERENCES}

1 Papsin BC. Cochlear implantation in children with anomalous cochleovestibular anatomy. Laryngoscope 2005;115:1-26.

2 Sennaroglu L. Cochlear implantation in inner ear malformations--a review article. Cochlear Implants Int 2010;11:4-41.

3 Wootten CT, Backous DD, Haynes DS. Management of cerebrospinal fluid leakage from cochleostomy during cochlear implant surgery. Laryngoscope 2006;116:2055-9.

4 Loundon N, Rouillon I, Munier N, et al. Cochlear implantation in children with internal ear malformations 2005;26:6.

5 Mehanna AMA, Fathala MF, Elwany MS. A stepwise algorithm for the management of cerebrospinal fluid gusher during cochlear implantation. Egypt J Otolaryngol 2015;31:19-29.

6 Vashist S, Singh S. CSF Gusher in cochlear implant Surgery-does it affect surgical outcomes? Eur Ann Otorhinolaryngol Head Neck Dis 2016;133(Suppl 1):S21-4.

7 Eftekharian A, Amizadeh M. Cerebrospinal fluid gusher in cochlear implantation. Cochlear Implants Int 2014;15:179-84.

Copyright 2021 BMJ Publishing Group. All rights reserved. For permission to reuse any of this content visit https://www.bmi.com/company/products-services/rights-and-licensing/permissions/

BMJ Case Report Fellows may re-use this article for personal use and teaching without any further permission.

Become a Fellow of BMJ Case Reports today and you can:

- Submit as many cases as you like

Enjoy fast sympathetic peer review and rapid publication of accepted articles

- Access all the published articles

Re-use any of the published material for personal use and teaching without further permission

\section{Customer Service}

If you have any further queries about your subscription, please contact our customer services team on +44 (0) 2071111105 or via email at support@bmj.com.

Visit casereports.bmj.com for more articles like this and to become a Fellow 